\title{
A neotype designation for the bone-skipper Centrophlebomyia anthropophaga (Diptera, Piophilidae, Thyreophorina), with a review of the Palaearctic species of Centrophlebomyia
}

\author{
Maurizio Mei', Daniel Whitmore², Giuseppe Lo Giudice',3, Pierfilippo Cerretti',3 \\ I Dipartimento di Biologia e Biotecnologie "Charles Darwin", Università di Roma "La Sapienza", Piazzale \\ A. Moro 5, I 00185 Rome, Italy 2 Department of Life Sciences, Natural History Museum, Cromwell Road, \\ London, SW7 5BD, UK 3 Centro Nazionale Biodiversità Forestale (CNBFVR) - Corpo Forestale dello Stato, \\ via Carlo Ederle 16/a, 37100 Verona, Italy
}

Corresponding author: Pierfilippo Cerretti (pierfilippo.cerretti@uniroma1.it)

Academic editor: Rudolf Meier | Received 26 February 2013 | Accepted 13 June 2013 | Published 17 June 2013

Citation: Mei M, Whitmore D, Lo Giudice G, Cerretti P (2013) A neotype designation for the bone-skipper Centrophlebomyia anthropophaga (Diptera, Piophilidae, Thyreophorina), with a review of the Palaearctic species of Centrophlebomyia. ZooKeys 310: 7-28. doi: 10.3897/zookeys.310.4914

\begin{abstract}
The European bone-skippers (Diptera: Piophilidae: Thyreophorina), long considered extinct, have recently been the object of much interest by dipterists after their unexpected rediscovery. Considerable faunistic work has been done on these flies in recent years. However, some nomenclatural and taxonomic issues still require attention. A neotype is designated for Thyreophora anthropophaga Robineau-Desvoidy, 1830 (now in the genus Centrophlebomyia Hendel, 1903) to fix the identity of this nominal species. Centrophlebomyia anthropophaga is recognized as a valid species. It is described and illustrated in detail, and information on its preimaginal instars is provided for the first time. Four Palaearctic species of Centrophlebomyia are recognized and reviewed and a key is provided for their identification. Centrophlebomyia orientalis Hendel, 1907 from northern India, is removed from synonymy with $C$. anthropophaga and recognized as a valid species of Centrophlebomyia, stat. r. The nominal genus Protothyreophora Ozerov, 1984 is considered a junior synonym of Centrophlebomyia, syn. $\mathbf{n}$.
\end{abstract}

\section{Keywords}

Neotype designation, new synonymy, Protothyreophora, preimaginal instars, life history, systematics

Copyright Maurizio Mei et al. This is an open access article distributed under the terms of the Creative Commons Attribution License 3.0 (CC-BY), which permits unrestricted use, distribution, and reproduction in any medium, provided the original author and source are credited. 


\section{Introduction}

It is undeniable that some organisms are able to provoke great curiosity, which may last through generations of students. There are several, often interrelated reasons for this: rarity for example, true or apparent, but also a certain aesthetic appeal or unusual biology. All of these factors have contributed to the long-term popularity of thyreophorine Piophilidae, particularly that of the European species. These unusual-looking flies, commonly known as bone-skippers, appear to be associated as necrophages with large vertebrate carrion, including human corpses, and have always been considered rare, almost legendary ( $c f$. Pape, 2009). The three European thyreophorines, Centrophlebomyia furcata (Fabricius, 1794), C. anthropophaga (Robineau-Desvoidy, 1830) and Thyreophora cynophila (Panzer, 1798), were even considered extinct for over a century. All three were rediscovered in the last 30 years, during which almost every record of a thyreophorine was published (Freidberg 1981; Michelsen 1983; Contini and Rivosecchi 1993; Gòmez-Gòmez et al. 2008; Martín-Vega and Baz 2011; Martín-Vega et al. 2010; Carles-Tolrá 2011; Carles-Tolrá et al. 2010, 2011, 2012; Zaldivar Ezquerro et al. 2011), sometimes with a certain media emphasis (Appendix 1). Despite the aura of exceptionality surrounding these flies, and the excitement their rediscovery has recently raised among dipterists, there is still some confusion concerning their taxonomy and nomenclature.

The present work was triggered by the finding of several specimens of a species of Centrophlebomyia Hendel, 1903 in central Italy (Monte Velino, Central Apennines), during a study on the necrophilous insect fauna associated with carrion (Lo Giudice, 2007). These specimens are conspecific with those recorded 25 years ago from Sardinia as C. anthropophaga (Contini and Rivosecchi 1993; Martín-Vega et al. 2010). However, their identification turned out to be trickier than expected and had to rely on the study of all known Palaearctic thyreophorines, including genus Protothyreophora Ozerov, 1984. This allowed us to review the taxonomy and nomenclature of the Palaearctic Thyreophorina, modifying the arrangement proposed for this group by Martín-Vega et al. (2010), and designating a neotype for $C$. anthropophaga. We also provide the first ever information on preimaginal instars of $C$. anthropophaga and an updated key to all Palaearctic species of the group.

\section{Material and methods}

\section{Specimens}

Male terminalia, pinned specimens and larvae were examined, uncoated, with a Hitachi TM1000 environmental scanning electron microscope (ESEM). Male terminalia were also slide mounted. Line drawings were made using a drawing tube. Figure 38 was prepared from composites of images captured using a DS-L1 digital camera (Nikon, Tokyo) mounted on a MZ 12.5 stereoscopic microscope (Leica, Wetzlar, Germany) and processed with Helicon Focus Pro software (Kharkov, Ukraine). 
Male terminalia were dissected following the method described by Cerretti \& Pape (2012) and, after examination, were preserved in glycerine in a plastic microvial pinned beneath the specimen.

The material examined is deposited in the following collections (acronyms as used in the text):

MZUR Museum of Zoology, Sapienza Università di Roma, Italy;

NHMW Naturhistorische Museum, Wien, Austria;

TAU Department of Zoology, Tel Aviv University, Tel Aviv, Israel;

ZMUC Natural History Museum of Denmark, Zoological Museum, University of Copenhagen, Denmark.

Label data of type specimens are given verbatim using the following symbols:

I end of a line and beginning of the next;

// end of a label and beginning of the next (from top to bottom on the same pin).

\section{Terminology}

Morphological terminology essentially follows Merz and Haenni (2000) except for the antenna, for which we follow Stuckenberg (1999). Measurements and ratios of the head follow Cerretti (2010).

\section{Results}

\section{Taxonomy}

Genus Centrophlebomyia Hendel, 1903

http://species-id.net/wiki/Centrophlebomyia

Figs $1-38$

Centrophlebomyia Hendel 1903: 216. [original description] - type species: Musca furcata Fabricius, 1794: 343, by original designation.

Thyreolepida Sack 1939: 4. [original description] - type species: Thyreolepida cinerea Sack, 1939:4, by original designation.

Protothyreophora Ozerov 1984a: 465. [original description] - type species: Protothyreophora grunini Ozerov 1984a, by original designation; syn. n. (see below).

References. Hendel 1903; McAlpine 1977; Ozerov 1984a; Ozerov 1984b; Ozerov 2000.

Recognition. Brownish, scathophagid-like flies, body length 4-8 mm. Body densely to moderately microtomentose and covered with long, fine setulae, especially 
in males. Frons with one or two upper reclinate orbital setae. Ocellar seta, medial and lateral vertical setae, and postvertical seta long and robust. Two to ten frontal setae usually arranged more or less regularly around lunula. Face with a strong, flattened median carina, antennal grooves deep. Parafacial with a patch of microtomentum at mid length (Fig. 15). Compound eye almost round in lateral view. Two pairs of strong vibrissae present, subequal in length and strength. Thoracic chaetotaxy as follows: $0-2$ postpronotal setae (postpronotal setae usually absent in male of $C$. furcata); $1+1$ intraalar, 1-2 + 3 strong dorsocentral setae, 1 postalar, 2 notopleural setae, $0-1$ prescutellar acrostichal setae. Scutellum long, dorsally flattened, much more developed in male than in female, with two pairs of setae, apical pair very long and strong, almost spiniform in larger males. Dorsal surface of scutellum bare. Development of scutellum in male related to body size. Propleural seta strong. Katepisternum densely setulose, with one strong katepisternal seta at upper posterior margin. Anepisternum with a row of setae along posterior margin, one of them strong. Thorax (except scutellum) very finely setulose throughout, besides the strong setae.

Wing membrane hyaline. Costa more or less spinose (i.e., with a regular row of stronger setulae interspersed with the general costal setulae), spine-like setae stronger in male than in female. Anal vein fading out well before wing margin. Legs thickly setulose in both sexes (almost woolly in male). Fore femur with 5-6 weak posteroventral setae near apex, scarcely differentiated in male. Hind femur with 2-3 anteroventral setae near apex. Mid tibia with five apical setae on ventral side: middle and lateral ones strongest. Hind tibia with one short, curved apical seta on posteroventral surface. Tarsi unmodified.

Preimaginal instars. Described by Freidberg (1981) and below.

Distribution. Europe, North Africa, Middle East, Russian Far East, northern India (Kashmir and Darjeeling).

Remarks. The generic diagnosis incorporates the characters given by McAlpine (1977) based only on the type species C. furcata.

\section{Included species}

Centrophlebomyia anthropophaga (Robineau-Desvoidy, 1830)

http://species-id.net/wiki/Centrophlebomyia_anthropophaga

Figs 1-4, 11, 12, 15-18, 22, 24-38

Thyreophora anthropophaga Robineau-Desvoidy 1830: 623 - type locality: Paris (France).

Type material examined. Neotype (designated below). Male (ZMUC), here designated, from Sardinia, Italy and bearing the following labels: SARDEGNA / Belvì (NU) / 10.X.'84 [3957.889'N, 9¹1.111'E] // Neotype ô / Thyreophora / anthropophaga / Robineau-Desvoidy, 1830 / M. Mei \& P. Cerretti des. 2013 // Centrophlebomyia / anthropophaga / (Robineau-Desvoidy, 1830) / M. Mei \& P. Cerretti det. 2013). 


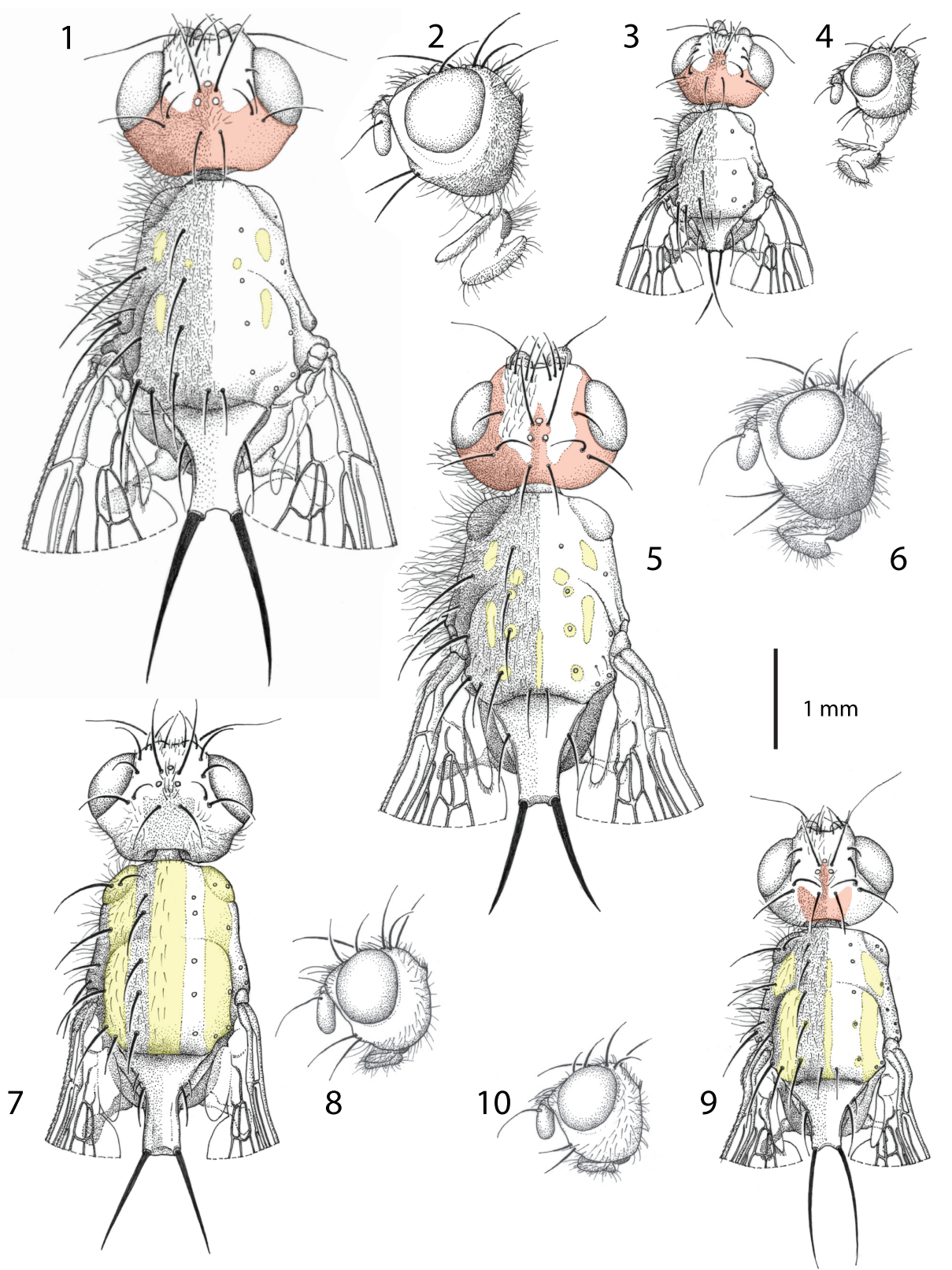

Figures I-I0. Males of Centrophlebomyia spp. I, 3, 5, 7, 9 head and thorax in dorsal view 2, 4, 6, 8, 10 head in lateral view I-4 C. anthropophaga (Italy) 5-6 C. furcata (Italy) 7-8 C. grunini (Russian Far East) 9-10 C. orientalis (India). In red the microtomentum pattern of head; in yellow the shiny, non microtomentose, pattern of thorax.

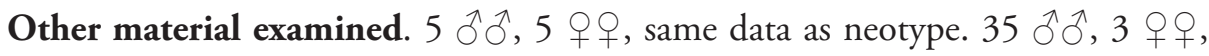
Italy, Abruzzo, L’Aquila province, Riserva Naturale Orientata Monte Velino, Man- 
dridi, $42^{\circ} 7.696^{\prime} \mathrm{N}, 13^{\circ} 22.247^{\prime} \mathrm{E}, 1270 \mathrm{~m}, 11 . X I .2005$, G. Lo Giudice, M. Mini, A.

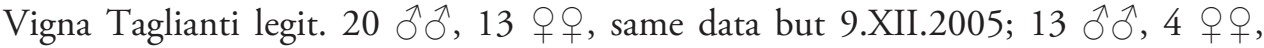

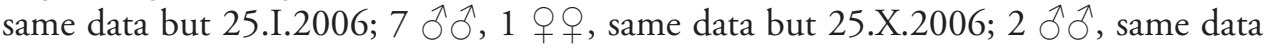

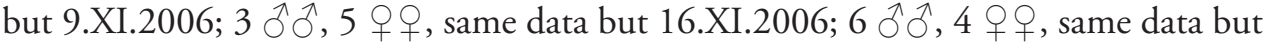
30.XI.2006; $2 \hat{\jmath} \widehat{\partial}$, same data but XI.2006 reared from larvae, (see below); $13 \hat{\delta} \widehat{\partial}, 2$ 우오, same data but 14.X.2007; $2 \hat{\jmath} \widehat{\jmath}$, same data but 18.XI.2008.

References. Michelsen 1983; Contini and Rivosecchi 1993; Martìn-Vega et al. 2010.

Remarks. Specimens from Sardinia were collected from a bag of dead, decaying snails (Contini and Rivosecchi, 1993). Specimens from central Italy were collected with hand net (adults) and pitfall traps (adults, larvae) filled with a saturated solution of water and salt $(\mathrm{NaCl})$, in a large fenced area where a feeding station ("vulture restaurant") was kept for a population of griffon vultures living in the Nature Reserve. Twenty pitfall traps were placed around dead and dismembered sheep (front and rear quarters without skin and guts).

Distribution. ?France (Paris), Italy (Sardinia, Central Apennines).

Redescription. Colouration. Head, including antenna and palpus, usually reddish yellow; sometimes dorsal half of occiput black. Occiput, ocellar triangle, genal dilation, and parafacial covered with microtomentum. When seen in dorsal view, the microtomentum that covers the occiput anteriorly outlines a three-pointed crown on the frons between the medial posterior margin of eyes (Figs 1, 3, 11, 12); middle tip of crown corresponds to anterior ocellus; lateral tips, laterally confined by eyes, end about level with posterior ocelli or slightly anteriorly. Prementum black. Postpronotum at least partly reddish laterally (reddish colour usually not visible in dorsal view). Scutum black in ground colour, covered with thin microtomentum except around base of dorsocentral setae and two lateral, longitudinal shiny vittae, widely interrupted at level of transverse suture (Figs 1,27) (suture well developed laterally up to level of dorsocentral row). Scutellum at least apically yellow. Legs usually entirely yellow, rarely tarsi darkened. Abdomen usually entirely yellow or light brown, but can vary from dark brown to shiny black dorsally in some females. Setae of whole body black. Wing hyaline.

Head (Figs 1-4, 11-12, 15, 27). Head about as wide as thorax. Eye almost round. Frons 2.0-2.5 times as wide as an eye in dorsal view. Parafacial $1 / 2-2 / 3$ as wide as first flagellomere, both measured at mid length. Gena, in profile, 0.33-0.65 times as high as eye. Medial vertical seta well developed, reclinate. Lateral vertical seta well developed, about $4 / 5$ of medial vertical seta, lateroclinate. One or (usually) two upper reclinate orbital setae; when two are present, then anterior one at most $1 / 3$ as long as posterior seta, and distinctly thinner. Postocellar seta strong and reclinate, subequal in size to ocellar and medial vertical setae. Ocellar seta proclinate. Anterior margin of frons with 2-3 pairs of pro- and medioclinate, strong frontal setae. Fronto-orbital plate with scattered, short, proclinate or medioclinate setae, between posteriormost upper reclinate orbital seta and distal margin of pedicel. Vibrissa double, very strong. Antenna shorter than height of facial ridge; first flagellomere 1.3-2.0 times as long as pedicel. Occiput and genal dilation covered 

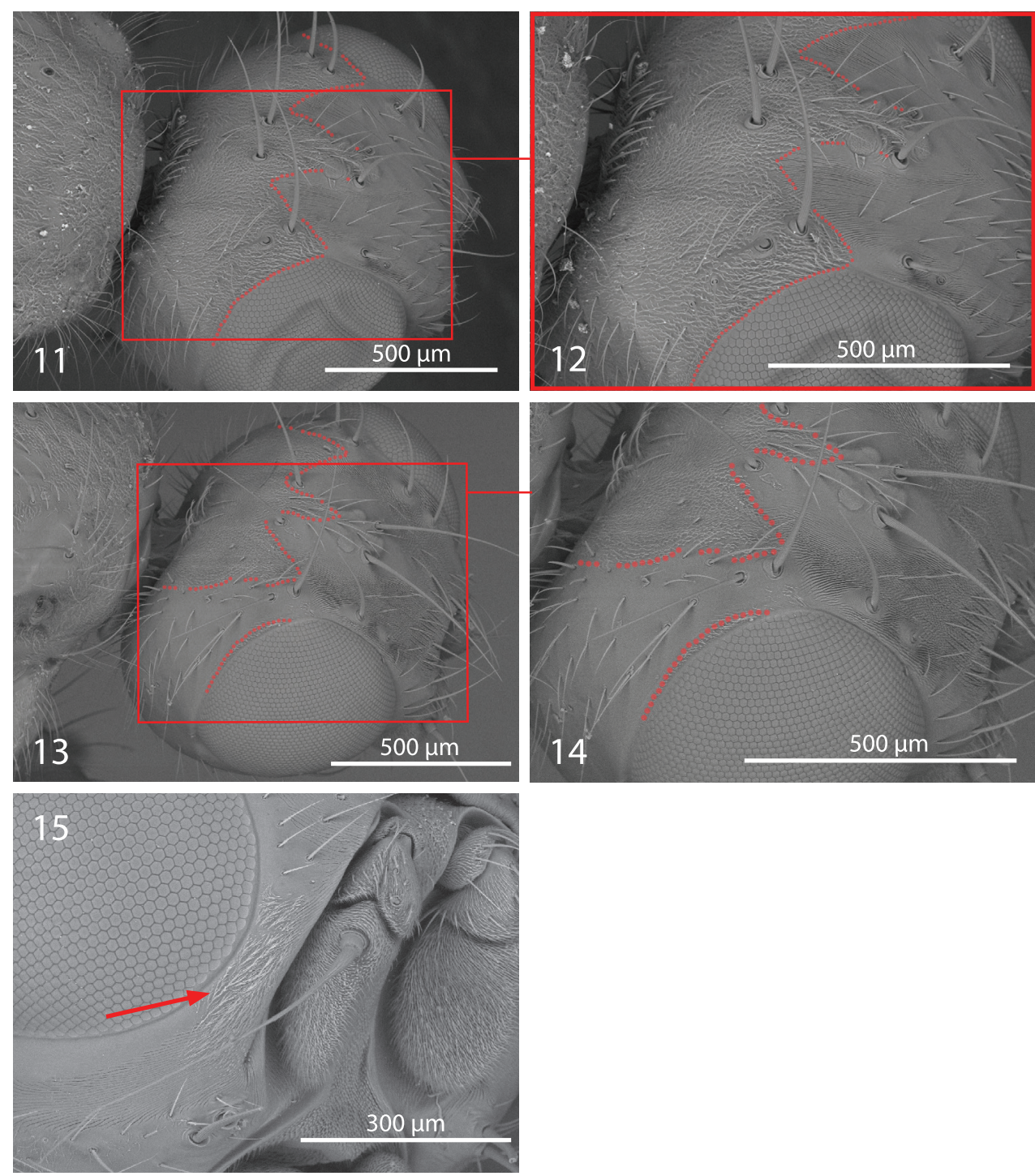

Figures II-I5. Centrophlebomyia spp. II-I4 head in dorsolateral view [dotted line indicates the border of microtomentum] II-I2 C. anthropophaga (Italy) I3-I4 C. orientalis (India) I5 C. anthropophaga (Italy), detail of head in anterodorsal view [arrow indicates microtomentum on parafacial].

with scattered black setae. Palpus well developed, apically clavate, covered with fine black setae.

Thorax (Figs 1, 3, 16, 17, 27). Thorax covered with fine black setulae, those on scutum distinctly shorter than those on pleurae. Postpronotum with or without 1-2 very fine setae in male (Fig. 16), usually with 2, relatively strong setae in female (Fig. 17). One strong presutural and 2 postsutural supra-alar setae; posterior postsutural supra-alar seta short and thin. One presutural and 3 postsutural dorso- 

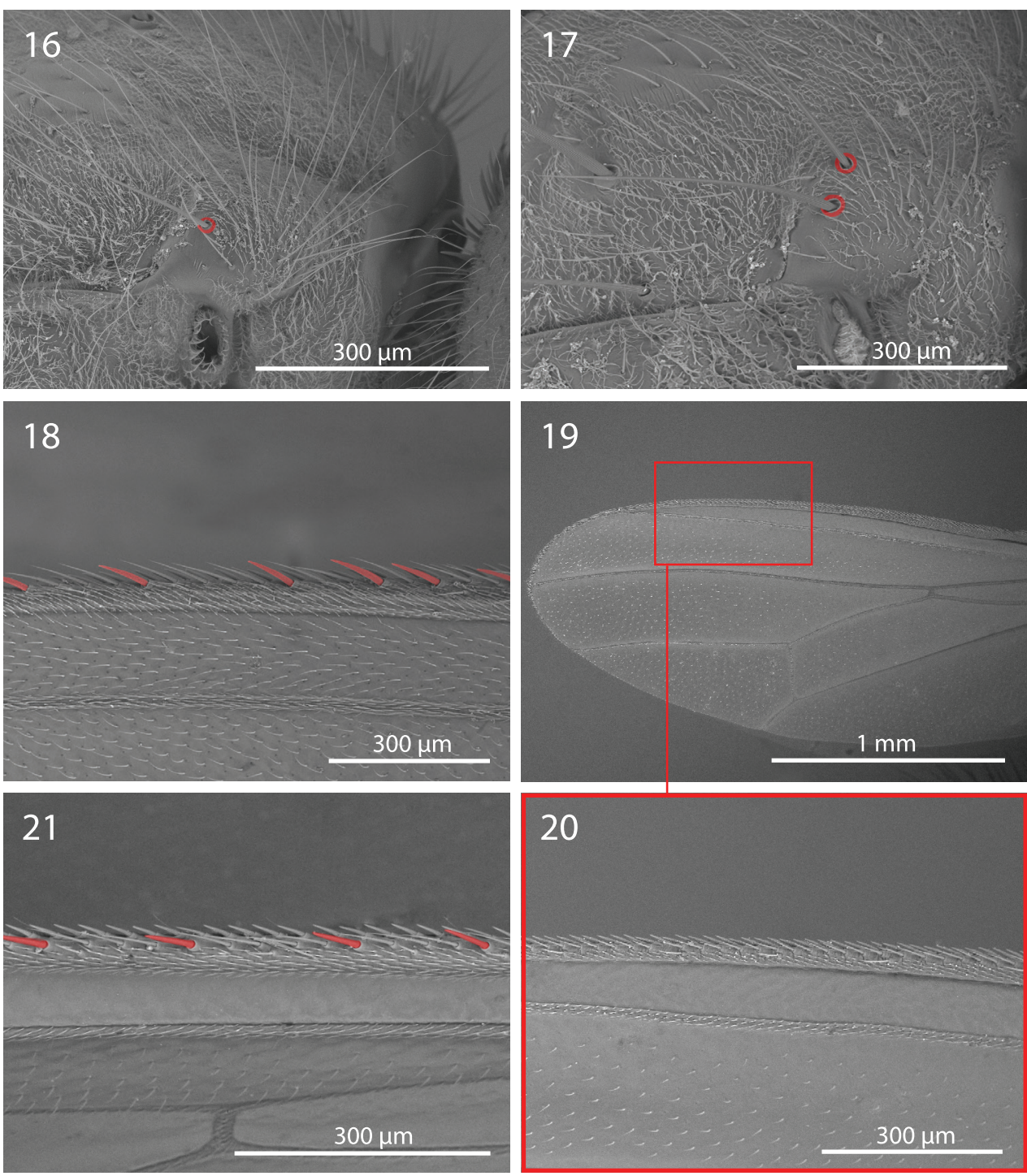

Figures 16-21. Centrophlebomyia spp. 16-17 C. anthropophaga (Italy), anterior part of thorax in dorsolateral view [red circles indicate postpronotal setae] $\mathbf{1 6}$ male $\mathbf{I} \mathbf{f e m a l e ~} \mathbf{~ 8 - 2} \mathbf{I}$ Wing $\mathbf{I 8}$ C. anthropophaga (Italy), detail of third costal sector $\left(\mathrm{Cs}_{3}\right)$ [in red the costal spine-like setae] 19-20 C. grunini (Russian Far East) $2 \mathbf{I}$ C. orientalis (India), detail of third costal sector $\left(\mathrm{Cs}_{3}\right)$.

central setae (Figs 1, 27) (2 postsutural dorsocentral setae may occur in smaller sized male specimens (Fig. 3)). One, short and weak, prescutellar acrostichal seta. Scutellum dorsally flat to slightly concave (ground plan trait of the Thyreophorina, McAlpine, 1977), more or less elongated posteriorly, with one lateral seta and one apical seta (Figs 1,3); lateral seta usually much smaller than apical seta. Shape and size of scutellum strongly variable (Figs 1, 3,27) between sexes and between males 

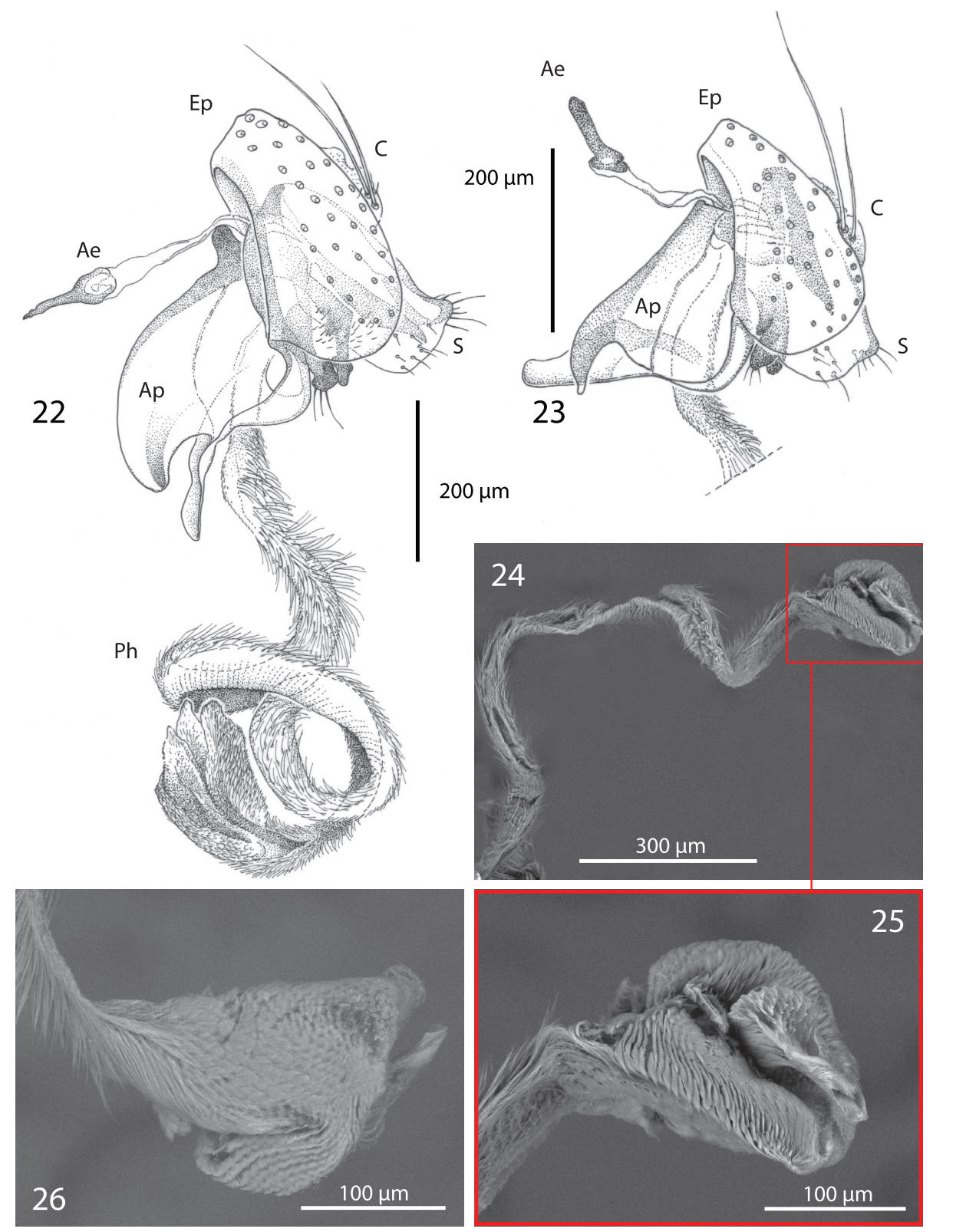

Figures 22-26. Male terminalia of Centrophlebomyia spp. [Ae = ejaculatory apodeme; $\mathbf{A} \mathbf{p}=$ phallapodeme; $\mathbf{C}=$ cerci; $\mathbf{E} \mathbf{p}$ = epandrium; $\mathbf{P h}=$ phallus; $\mathbf{S}$ = surstylus] $\mathbf{2 2}$ C. anthropophaga (Italy) $\mathbf{2 3}$ C. orientalis (India) 24-26 C. anthropophaga (Italy), phallus.

of different sizes (Figs 1, 3). Two notopleural setae. One anepisternal seta. One katepisternal seta. Legs robust, covered with long and fine setulae. Mid tibia with 3-5 robust ventral preapical setae. Claws well developed in both sexes, about as 

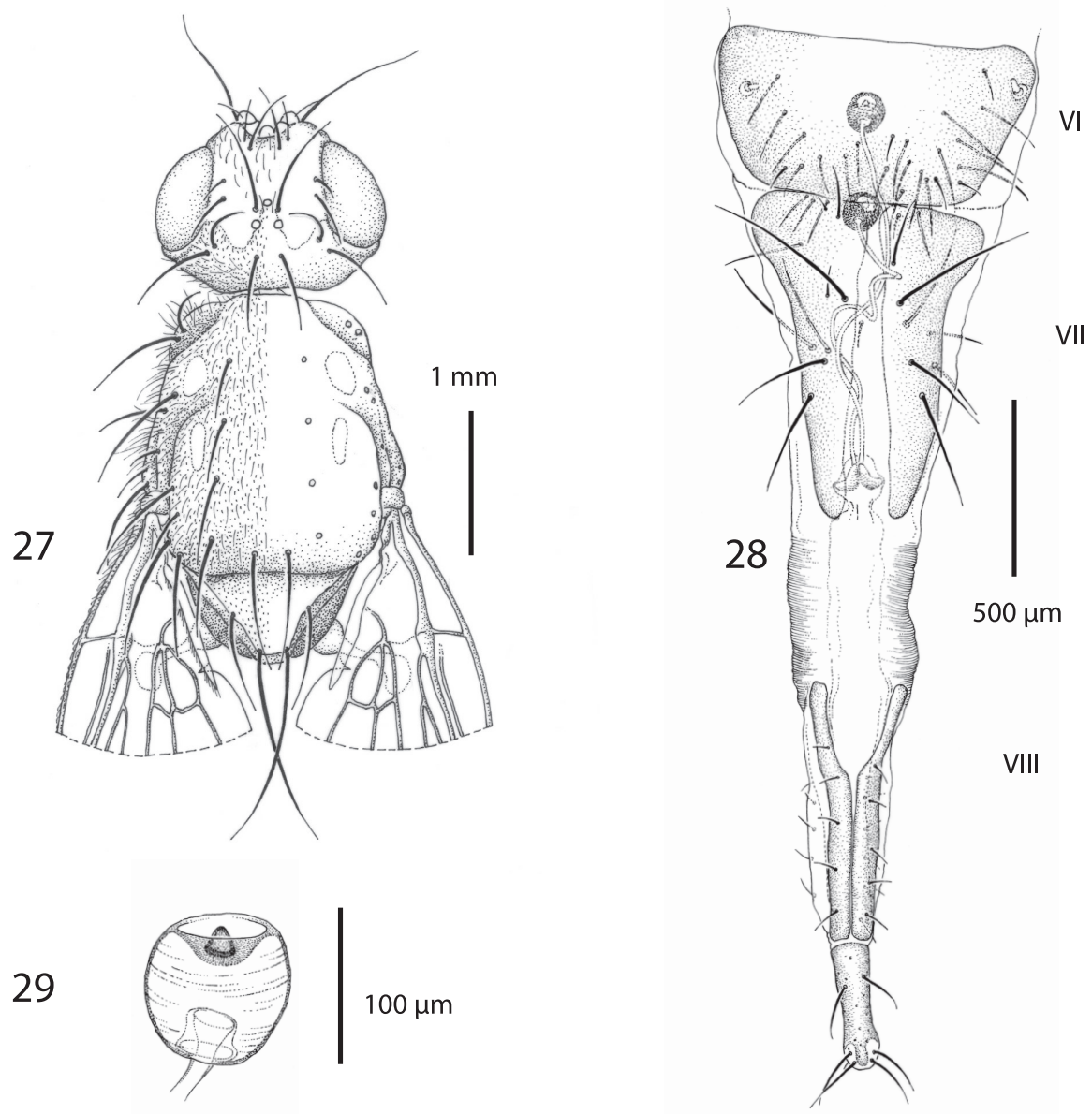

Figures 27-29. Female of Centrophlebomyia anthropophaga (Italy) 27 head and thorax in dorsal view $\mathbf{2 8}$ ovipositor in dorsal view $\mathbf{2 9}$ spermatheca.

long as fifth tarsal segment in male, varying in length between 0.5 and 0.7 times as long as fifth tarsal segment in female. Ventral row of costal setae (specifically $\mathrm{CS}_{3}$ ) characterized by the presence of some longer and stouter setae placed at more or less regular intervals (Fig. 18).

Abdomen. Male: more or less elongated; tergite 1 laterodorsally covered with short erect hair-like setae, medially bare; tergites 2 and 3 laterodorsally and ventrally covered with long, hair-like setae that become shorter toward the midline of tergites. Tergites 4 and 5 evenly covered with long, erect hair-like setae. Female: abdominal setae distinctly shorter.

Male terminalia (Figs 22, 24-26). Epandrium short and convex. Surstyli massive, almost touching each other posteromedially; distal margin of surstylus slightly bent pos- 

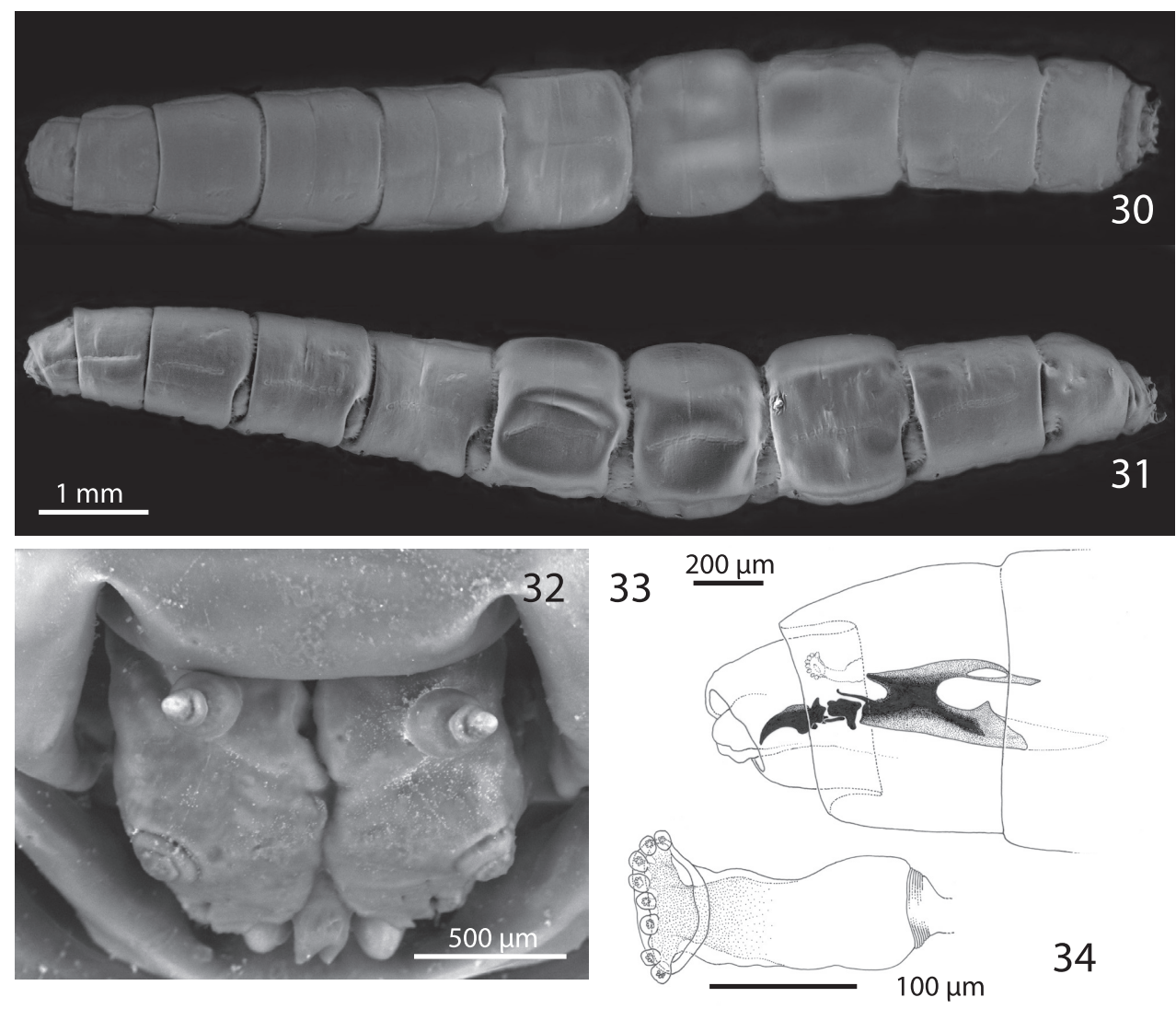

Figures 30-34. Third instar of Centrophlebomyia anthropophaga (Italy) 30 habitus in dorsal view $\mathbf{3 I}$ habitus in lateral view $\mathbf{3 2}$ head in frontal view $\mathbf{3 3}$ cephalopharyngeal skeleton in lateral view $\mathbf{3 4} \mathrm{aQn}$ terior spiracle in lateral view.

teriorly. Cerci very small, bearing long setae. Phallapodeme, in lateral view, very large with an evenly convex dorsal margin (Fig. 22). Pregonite well sclerotized, relatively narrow and slightly bent posteriorly; basally fused to hypandrium; pregonite with 1-2 fine setae distally. Postgonite very long, well sclerotized and evenly bent anteriorly. Pregonite and postgonite pincer-like in relative position, almost touching each other distally. Epiphallus attached basally and well developed. Basiphallus very long, tubular, covered with fine pubescence and membranous. Distiphallus massive, slightly sclerotized, covered with fine pubescence as in basiphallus; distiphallus with two large laterodistal lobes.

Female terminalia (Figs 28-29). Ovipositor long and telescopically retracted within fifth segment. Tergites 6 and 7 relatively wide and more or less flattened. Tergite 8 longitudinally divided into two halves. Cerci not differentiated. Two rounded and well sclerotized spermathecae.

Description of third instar and puparium. Both the larva and puparium of C. anthropophaga (Figs 30-38) correspond well to features given by McAlpine 

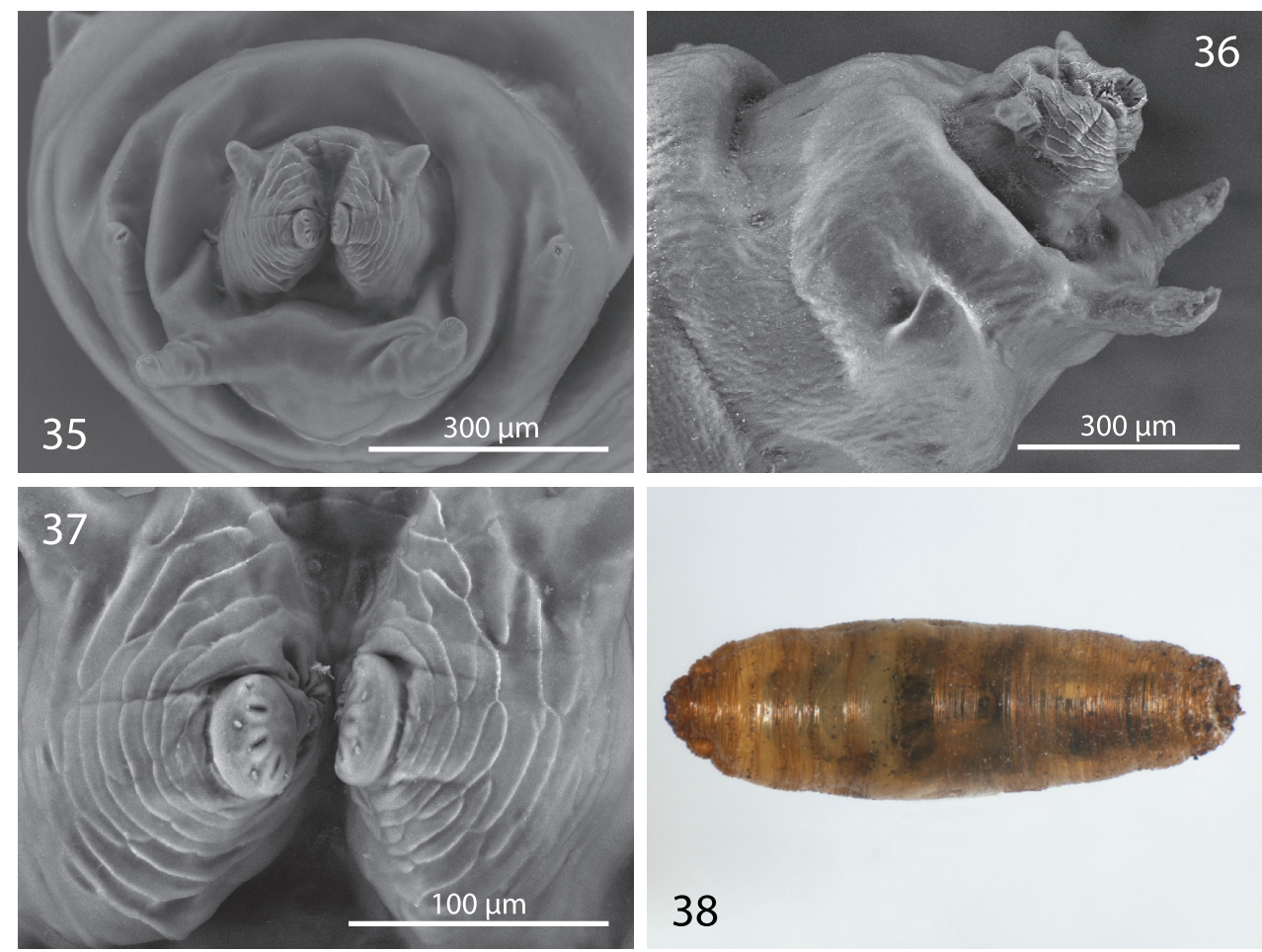

Figures 35-38. Third instar and puparium of Centrophlebomyia anthropophaga (Italy) 35 last segment bearing posterior spiracle in posterior view $\mathbf{3 6}$ last segment bearing posterior spiracle in lateral view $\mathbf{3 7}$ posterior spiracles in posterior view $\mathbf{3 8}$ puparium in dorsal view.

(1977), Ozerov (2000) and Ozerov and Norrbom (2010) for other piophilids and by Freidberg (1981) for C. furcata. Here we provide additional information not given in previous descriptions. Nearly all the segments of the third instars have a lateral "dotted" line composed of microscopic, concave structures which may be sensory organs (Fig. 31). Their shape and position suggest that they may be mechanoreceptors of pressure or stretching. These structures have not been noted in previous descriptions of piophilid larvae; they were either overlooked or are unique to $C$. anthropophaga.

Notes on larval development. On April $5^{\text {th }}(\mathrm{n}=15)$ and May $3^{\text {rd }}(\mathrm{n}=7), 2006$, several mature larvae were collected from the soil a few centimetres below the sheep quarters used as bait for the pitfall traps set in the "vulture restaurant" (see above under "Remarks"). The larvae were then transferred into two petri dishes (12 cm diameter): one filled with potting soil, the other with natural soil collected with the larvae from under the carcass. Moisture was provided each week until midsummer. All larvae remained active, though only slightly so, during this time. By June $1^{\text {st }}$, five out of 22 larvae had died. The loss of larvae continued steadily and by the beginning of September only six 
larvae were left, three in the potting soil and three in the natural soil. In early October 2006, two puparia were found in each dish and all the remaining larvae were dead. The four puparia and small amounts of soil were isolated in smaller dishes. An adult male emerged in November from one of the puparia in the natural soil, and another adult (possibly a male) was found dead in its puparium in the potting soil. The remaining two puparia failed to produce adults.

Our observations are consistent with those of Freidberg (1981; 2010 pers. comm.) on $C$. furcata larvae reared in Israel. Mature C. furcata larvae remained buried in the soil through spring and summer, estivating in this stage or as prepupae, and pupariated at the beginning of autumn. The larvae did not feed but were still more or less active. Most of the larvae died during the summer months and only very few adults emerged in October.

\section{Centrophlebomyia furcata (Fabricius, 1794)}

http://species-id.net/wiki/Centrophlebomyia_furcata

Figs 5-6

Musca furcata Fabricius, 1794: 343 - type locality: "habitat in Gallia".

Thyreolepida cinerea Sack, 1939: 4 - type locality: "Rehoboth [Rehovot] bei Jaffa" (Israel).

Material examined. 1 q, 1 ô, Israel, Tel Aviv, 17.XII.1977, A. Freiberg legit (MZUR); several males and females, same data (TAU). $16 \delta^{\lambda} \bar{\jmath}, 9$ 우, Italy, Latium, Monti della

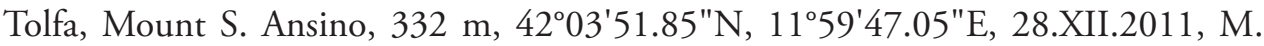
Mei legit, on dead sheep (MZUR).

References. Hendel 1903; McAlpine 1977; Freidberg 1981; Ozerov 2000; Martìn-Vega et al. 2010.

Distribution. Europe: Austria, Cyprus, France, Germany, Greece, Italy, Spain, United Kingdom; North Africa: Algeria; Middle East: Turkey, Israel.

Centrophlebomyia grunini (Ozerov, 1984), comb. n. http://species-id.net/wiki/Centrophlebomyia_grunini

Figs 7-8, 19-20

Protothyreophora grunini Ozerov 1984a: 466 - type locality: “Амурская област, Г. ЗеЯ” [= Amur region, near Zeya].

Material examined. $1 \hat{\sigma}, 1 \uparrow$, each bearing the following labels: [Russia] Амурская об̆ $\Lambda$ aст $]$ / Г. ЗеЯ [= Amur region, Zeya.] 1.VIII.1981/A. Ozerov/ PARATYPE (ZMUC).

References. Ozerov 1984a, 2000.

Distribution. Russian Far East. 
Centrophlebomyia orientalis (Hendel, 1907), stat. r.

Figs 9-10, 13-14, 21, 23

Centrophlebomyia orientalis Hendel 1907: 243 - type locality: "Indien, Darjeeling, am Himalaya".

Treated as junior synonym of anthropophaga Robineau-Desvoidy, 1830 by Martìn-

Vega et al. (2010: 611).

Type material examined. Holotype male, bearing the following labels: [INDIA] Darjeeling / Juni / Frusthofer leg. // Centrophlebomyia / orientalis / Hendel [handwritten] // Type [red label] // Holotypus [red label] // Pseudotyreo- / phora orientalis / Hendel / A. Ozerov det., 1984 (NHMW).

Other material examined. INDIA (Kashmir) Gulmarg, 2600-3000 m, 17.VIII 5.IX.1978: 2 ふぇ, 1 ㅇ (ZMUC).

References. Hendel 1907; Michelsen 1983; Ozerov 2000.

Distribution. Northern India (Darjeeling, Kashmir).

\section{Key to species of Centrophlebomyia}

1 Scutum mostly shiny black with two large, longitudinal, silver stripes of microtomentum aligned with, and along the entire length of, dorsocentral setae (Fig. 7 [where the three shiny black vittae are yellow highlighted]). Head almost entirely smooth, katepisternum without microtomentum. Costal vein without spine-like setae (Figs 19-20). [Gena 0.44-0.47 times as high as eye in lateral view (Fig. 8)].

C. grunini (Ozerov) comb. n.

- $\quad$ Scutum usually more extensively covered with microtomentum, and not showing the pattern described above (Figs 1, 3, 5, 9, 27). Head microtomentose at least on medial dorsal portion of postcranium, katepisternum at least partly microtomentose (e.g., dorsal and posterior to base of katepisternal seta). Ventral row of costal setae characterized by some longer and stouter (spine-like) setae placed at more or less regular intervals, especially on $\mathrm{Cs}_{3}$

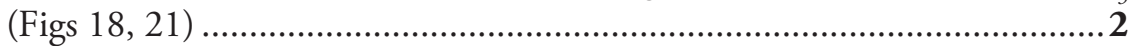

2 Gena 0.68-0.95 times as high as eye in lateral view (Fig. 6). One upper reclinate orbital seta (Figs 5, 6). Genal dilation and occiput entirely covered with microtometum. Occipital microtomentum extends anteriorly on fronto-orbital plate as shown in Fig. 5 [in red]. One presutural dorsocentral seta (Fig. 5). Katepisternum entirely covered with microtomentum. Male: postpronotal setae not differentiated (Fig. 5)....

C. furcata (Fabricius)

- $\quad$ Gena 0.33-0.65 times as high as eye in lateral view (Figs 2, 4, 10). Two upper reclinate orbital setae (exceptionally only one in C. anthropophaga) (Figs 2, 4, 10). Occipital microtomentum never extending anteriorly on fronto-orbital plate (Figs 1, 3, 9 [in red]). Occipital microtomentum extends anteriorly on 
frons as shown in Figs 1, 3, 9, 11-14 [in red]. One or two presutural dorsocentral setae. Katepisternum varying from entirely covered with microtomentum to largely smooth. Male: postpronotal setae well developed .................. 3

3 Genal dilation and occiput entirely covered with microtometum (Figs 1, 3, 11,12 [in red]). Occipital microtomentum extends anteriorly on frons as shown in Figs 1, 3, 11, 12 [in red]. One presutural dorsocentral seta (Figs 1, 3, 27). Katepisternum entirely covered with thick microtomentum. Usually two upper reclinate orbital setae, the anterior one very short and weak (Figs 2,4 ) (only one upper reclinate orbital seta present in a few specimens from Sardinia). Male: phallapodeme, in lateral view, with an evenly convex dorsal margin and posterior tip lobe-like (Fig. 22); one or rarely two hair-like postpronotal setae. anthropophaga (Robineau-Desvoidy) Genal dilation entirely smooth, occiput largely without microtomentum laterally (Figs 9, 13, 14 [where microtomentum is red highlighted]). Occipital microtomentum extends anteriorly on frons as shown in Figs 9, 13, 14 [in red]. Two presutural dorsocentral setae (Fig. 9). Katepisternum almost entirely smooth. Two upper reclinate orbital setae, the anterior one distinctly shorter but somewhat stout (Fig. 10). Male: phallapodeme, in lateral view, with an almost straight dorsal margin, posterior tip narrow and hook-like (Fig. 23); two strong postpronotal setae... orientalis (Hendel)

\section{Discussion and conclusion}

\section{The neotype designation of "anthropophaga"}

Martín-Vega et al. (2010) recognised two species in the genus Centrophlebomyia: Centrophlebomyia furcata (Fabricius, 1794), found in Europe, North Africa and the Near East, and C. anthropophaga (Robineau-Desvoidy, 1830) (with Centrophlebomyia orientalis Hendel, 1907 in synonymy), known from Paris (France), Sardinia (Italy) and northern India.

Centrophlebomyia anthropophaga was described by Robineau-Desvoidy (1830, in Thyreophora) "based solely on his memory of specimens he had observed in large numbers destroying preparations of human muscles, ligaments and bones in the Paris School of Medicine in August 1821" (Martín-Vega et al. 2010: 611). The original description is too general and inadequate to properly characterize the species and, as usual for Robineau-Desvoidy, there are no illustrations. No type material exists because no specimens were collected at the time the observations were made. Hence, the true identity of this nominal species has remained uncertain. It was treated as an "invalid" (in the sense of "unavailable") name in the Catalogue of Palaearctic Diptera (Papp, 1984), but was correctly interpreted as an available name according to the present Code (ICZN 1999) by Martìn-Vega et al. (2010). Just prior to the appearance of the Catalogue, the name anthropophaga was resurrected by Michelsen (1983) 
("with a rather bold assumption", see Martín-Vega et al. 2010: 611) for specimens of a thyreophorine species collected in Kashmir. This name was used also by Contini and Rivosecchi (1993) for specimens of Centrophlebomyia collected in Sardinia that were considered conspecific with those of Michelsen (see also Rivosecchi, 2008). The existence of $C$. orientalis, a nominal species briefly described by Hendel (1907) from Darjeeling (West Bengal, India), appears to have escaped the attention of these authors also because not listed in the catalogues. Ozerov (2000), in his review of the Palaearctic Piophilidae, treated the specimens from Kashmir (Michelsen, 1983) and Sardinia (Contini \& Rivosecchi, 1993) as C. orientalis. Ozerov (2004) later recognized only C. furcata in Europe and recorded it from Sardinia and Czech Republic. In the most recent treatment of Centrophlebomyia, Martín-Vega et al. (2010) considered Centrophlebomyia from Sardinia and India as conspecific under the name $C$. anthropophaga and formally placed C. orientalis in synonymy. It is noteworthy that Contini \& Rivosecchi (1993) never studied the material of Michelsen (1983), only his drawings and descriptions, and neither Ozerov (2000) nor Martín-Vega et al. (2010) studied the Sardinian specimens.

Our study shows that specimens of Centrophlebomyia from Sardinia and central Italy are conspecific and are different from both $C$. orientalis and $C$. furcata, so we here propose to remove orientalis Hendel from synonymy with anthropophaga Robineau-Desvoidy.

Furthermore, considering the confused taxonomic and nomenclatural situation described above, created by Michelsen's (1983) resurrection of the name anthropopha$g a$ and by the subsequent repeated use of this name (Contini and Rivosecchi,1993; Martìn-Vega et al., 2010), we see a need to designate a neotype to fix once and for all the identity of this nominal species.

Considering that:

i) Centrophlebomyia anthropophaga's original description is vague and insufficient, and no type specimens ever existed in collections as no actual specimen was ever collected;

ii) The name anthropophaga is nomenclaturally available according to the International Code of Zoological Nomenclature (1999);

iii) Michelsen (1983) convincingly showed that Robineau-Desvoidy's original description of $C$. anthropophaga is a poor match with $C$. furcata (the only other european species known at the time) but provides a reasonable fit with his Kashmir material (i.e., with C. orientalis);

iv) Robineau-Desvoidy's original description of $C$. anthropophaga is not inconsistent also with characters shown by the Italian specimens;

v) The Centrophlebomyia from Italy is not conspecific with $C$. orientalis, the species dealt with by Michelsen (1983), nor with C. furcata, and is actually an unnamed species;

vi) The specimens from Sardinia were already referred to under the name anthropophaga by Contini and Rivosecchi (1993) and Martìn-Vega et al. (2010); 
we select as neotype a male specimen from Sardinia chosen among those studied by Contini and Rivosecchi (1993). As no French or European material of C. anthropophaga (sensu this paper) is known to exist, our choice of a Sardinian specimen is essentially as near as practicable to the original type locality, thereby fulfilling Article 75.3.6 of the Code (ICZN 1999). We refrain from proposing a new name for the Italian species because it would not resolve the problem of the name anthropophaga, that would remain available and valid, though not associated with type specimens nor unambiguously attributable to a known species.

\section{Protothyreophora as a junior synonym of Centrophlebomyia}

The thyreophorine genus Protothyreophora was proposed by Ozerov (1984a) for the single species $P$. grunini, stressing that it is distinct from Centrophlebomyia in having two upper reclinate orbital setae instead of only one, two presutural dorsocentral setae instead of one, a distinctive pattern of thoracic microtomentum and the costal vein without any spine-like setae distally. This shows that Ozerov based his definition of Centrophlebomyia exclusively on characters of the type species $C$. furcata. Our examination of specimens of $C$. orientalis shows that this species has 2 upper reclinate orbital setae and 2 presutural dorsocentral setae, as in C. grunini. Moreover, the spine-like setae on the costa in thyreophorines may vary also between males and females of the same species (C. furcata), and be present or absent in different species of the same genus (Piophilosoma Hendel). The characteristic pattern on the thorax of C. grunini (Fig. 7), with two longitudinal bands of grey microtomentum along the line of the dorsocentral setae, contrasting with the remaining smooth surface, can be interpreted as having evolved from the pattern found in other species of Centrophlebomyia (small smooth areas lacking microtomentum, feebly developed in $C$. furcata and $C$. anthropophaga but much more extensive in $C$. orientalis) (Figs 1, 5, 9).

For these reasons, we consider the monotypic genus Protothyreophora as a junior synonym of Centrophlebomyia.

\section{Concluding remarks}

The European thyreophorine species have always been considered very rare insects and have famously also been considered as locally or even globally extinct (Cogan and Dear 1975; Fontaine et al. 2007; Pape 2009). We still know almost nothing about the biology, ecology and distribution of these flies, due both to their apparent rarity and the lack of targeted research. It was known for a long time (e.g., Robineau-Desvoidy 1842, 1849) that thyreophorine species have a winter phenology and are preferentially associated with large carcasses in an advanced state of decay, but for many decades there was no attempt to use this information to launch determined searches for these insects. The first detailed study was that of Freidberg (1981) on the biology of C. furcata in 
Israel. Additional data were published on C. grunini in the Russian Far East by Ozerov (1984b), and only in the last few years are we beginning to understand the ecology of Thyreophora cynophila after its rediscovery in Spain (Carles-Tolrá et al. 2010; MartínVega and Baz 2011). Further studies are necessary to increase our knowledge of the ecology of these flies and to assess their conservation status.

It would seem that these flies may also be relatively abundant in sites where they are present (Freidberg 1981; Carles-Tolrá et al. 2010; and authors pers. obs.), but in general they seem to be very localized and living at low population densities. Martín-Vega and Baz (2011) noted the role of "vulture restaurants" and protected areas in maintaining populations of bone-skippers, but they considered other measures to be necessary as well, such as different management practices of livestock and wild ungulates aimed at naturally generating a constant availability of large carcasses. As mentioned above, C. anthropophaga was also collected by us in a "vulture restaurant", where it was present in abundance, but we have no further information on the presence of this species elsewhere in central Italy. Centrophlebomyia furcata was collected by one of us (MM) in a rather remote area characterized by a considerable and continuous presence of wild cattle, sheep and horses, and where carcasses of such large animals that died naturally are regularly present.

It would also be interesting to assess the role of food sources other than large mammal carcasses in maintaining natural populations of these flies. Other studies have shown that thyreophorine species have also been collected from a bag of dead decaying snails (C. anthropophaga: Contini \& Rivosecchi, 1993), dead rodents (C. grunini: Ozerov, 1984a), traps baited with dead squids (T. cynophila: Martín-Vega et al., 2010), and a dead bird (Carles-Tolrá 2011). This would seem to indicate that these alternative food sources may play some role in maintaining populations of these insects.

We hope that the interest generated by the recent rediscovery of these flies will result in further studies on their reproductive biology and ethology, as combining the results of such studies with the already available morphological data may help explain the great polymorphism observed in adult males.

\section{Acknowledgements}

Most sincere thanks are due to J.E. O'Hara (Canadian National Collection of Insects, Ottawa, Canada) and two anonymous reviewers for their constructive comments on earlier drafts of this manuscript, to A. Minelli (Padova University, Italy), T. Pape and $\mathrm{V}$. Michelsen (ZMUC) for their very useful and appreciated advice during the course of this study. Many thanks also to T. Pape (ZMUC), P. Sehnal (NHMW), A. Freidberg (TAU) and L. Rivosecchi (Rome, Italy), who allowed us to study the material under their care; to Tiziana Altea, Luciano Sammarone, Mario Posillico, Rosario Bartolo and Vincenzo Cofini (Riserva Nazionale Orientata Monte Velino, Abruzzo, Italy) who facilitated access and field work in the Reserve; to M. Mini (Rome, Italy) for help collecting the material; to Angela Cerasoli (Vienna) for assistance in examining the 
holotype of $C$. orientalis. The authors also thank F. Mason (Italian National Forestry Service, Verona, Italy) and A. Vigna Taglianti (MZUR) for their constant support of our research activities in the Central Apennines.

\section{References}

Carles-Tolrá M (2011) Primera cita de Thyreophora cynophila (Panzer) sobre cadáveres de aves (Diptera: Piophilidae: Thyreophorina). Boletín de la Sociedad Entomologica Aragonesa, 49: 355-356.

Carles-Tolrá M, Cañete Saiz FJ (2012) Primera cita de Thyreophora cynophila (Panzer) para la provincia de Cuenca (España) (Diptera: Piophilidae: Thyreophorina). Boletín de la Sociedad Entomologica Aragonesa, 50: 254.

Carles-Tolrá M, Compaired F, Vlasco J (2011) Thyreophora cynophila (Panzer), Centrophlebomyia furcata (fabricius) and other dipterans associated to winter carcasses (Insecta: Diptera). Boletín de la Sociedad Entomologica Aragonesa, 48: 217-220.

Carles-Tolrá M, Rodriguez PC, Verdù J (2010) Thyreophora cynophila (Panzer, 1794): collected in Spain 160 years after it was thought to be extinct (Diptera: Piophilidae: Thyreophorini). Boletín de la Sociedad Entomologica Aragonesa, 46: 1-7.

Cerretti P (2010) I tachinidi della fauna italiana (Diptera Tachinidae), con chiave interattiva dei generi ovest-paleartici. Volume I, 573 pp., Volume II, 339 pp. + CD-ROM. Cierre Edizioni, Verona.

Cerretti P, Pape T (2012) Phylogenetics and taxonomy of Ventrops - the largest genus of Afrotropical Rhinophoridae (Diptera). Invertebrate Systematics, 26(3): 274-292. doi: $10.1071 /$ IS 12001

Cogan BH, Dear JP (1975) Additions and corrections to the list of British Acalypterate Diptera. Entomologist's Monthly Magazine, 110: 173-180.

Contini C, Rivosecchi L (1993) Sulla presenza in Sardegna di Centrophlebomyia anthropophaga (Rob. Desv., 1830) (sensu Michelsen, 1983) (Diptera Thyreophoridae). Fragmenta entomologica, 25: 275-280.

Fabricius JC (1794) Entomologia Systematica emendata et aucta. Vol. 4. Hafniae [= Copenhagen], $472+\mathrm{i}-\mathrm{vi}+1 \mathrm{pp}$.

Fontaine B, Bouchet P, van Achterberg K (2007) The European union's 2010 target: putting rare species in focus. Biological Conservation, 139: 167-185. doi: 10.1016/j.biocon.2007.06.012

Freidberg A (1981) Taxonomy, natural history and immature stages of the bone-skipper, Centrophlebomyia furcata (Fabricius) (Diptera: Piophilidae, Thyreophorina). Entomologica Scandinavica, 12: 320-326. doi: 10.1163/187631281794709728

Gomez-Gomez A, Diaz-Aranda LM, Michelsen V (2008) Rediscovery of Centrophlebomyia furcata (Fabricius, 1794) (Diptera: Piophilidae) in Europe. Studia dipterologica, 15(1/2): 231-237.

Hendel F (1903) Centrophlebomyia nov. gen. Thyreophorinae. Zeitschrift für systematische Hymenopterologie und Dipterologie, 3: 215-216. 
Hendel F (1907) Neue und interessante Dipteren aus der kaiserl. Museum in Wien. Wiener Entomologische Zeitung 26(7-9): 245.

International Commission on Zoological Nomenclature (1999) International Code of Zoological Nomenclature. Fourth edition adopted by the International Union of Biological Sciences. International Trust for Zoological Nomenclature, London. xxix +306 pp.

Lo Giudice G (2007) Studio di una comunità di Ditteri necrofagi nel Massiccio del VelinoSirente (Appennino Centrale). Degree thesis (not published), supervisor A. Vigna Taglianti, Facoltà di Scienze Matematiche, Fisiche e Naturali, Università degli Studi di Roma "La Sapienza”, 114 pp.

Martín-Vega D, Baz A, Michelsen V (2010) Back from the dead: Thyreophora cynophila (Panzer, 1798) (Diptera: Piophilidae) "globally extinct" fugitive in Spain. Systematic Entomology, 35(4): 607-613. doi: 10.1111/j.1365-3113.2010.00541.x

Martín-Vega D, Baz A (2011) Could the "vulture restaurants" be a lifeboat for the recently rediscovered bone-skippers (Diptera, Piophilidae). Journal of Insect Conservation, 15(5): 747-753. doi: 10.1007/s10841-011-9429-0

McAlpine JF (1977) A revised classification of the Piophilidae, including "Neottiophilidae" and "Thyreophoridae" (Diptera: Schizophora). Memoirs of the Entomological Society of Canada, 103: i-vi, 1-66.

Merz B, Haenni JP (2000) 1. 1. Morphology and terminology of adult Diptera (other than terminalia). In: Papp L, Darvas B (Eds) Contribution to a Manual of Palaearctic Diptera (with special reference to flies of economic importance). Vol. 1. General and Applied Dipterology. Science Herald, Budapest: 21-51.

Michelsen V (1983) Thyreophora anthropophaga Robineau-Desvoidy, an "extinct" bone-skipper rediscovered in Kashmir (Diptera: Piophilidae, Thyreophorina). Entomologica Scandinavica, 14: 411-414. doi: 10.1163/187631283X00173

Ozerov AL (1984a) A new Palearctic genus of the family Thyreophoridae (Diptera) from the Soviet Far East [in Russian]. Zoologicheskii Zhurnal, 63(3): 464-466.

Ozerov AL (1984b) К биологии Protothyreophora grunini Ozerov (Diptera, Thyreophoridae). Аоклады высшей школы. Биологические науки. № 4, С. 39-41. [The biology of Protothyreophora grunini Ozerov (Diptera, Thyreophoridae). Reports of the High School. Biological sciences, 4: 39-41.]

Ozerov AL (2000) A.9. Family Piophilidae. In: Papp L, Darvas B (Eds) Contributions to a manual of Palearctic Diptera. Appendix. Science Herald, Budapest: 355-365.

Ozerov AL (2004) Fauna Europaea: Piophilidae. In: Pape T (Ed) Fauna Europaea: Diptera Brachycera. Fauna Europaea version 2.4, http://www.faunaeur.org [accessed 23 January 2013]

Ozerov AL, Norrbom AL (2010) Piophilidae. In: Brown BV, Borkent A, Cumming JM, Wood DM, Woodley NE, Zumbado M (Eds). Manual of Central American Diptera. Ottawa, Canada: National Research Council Press: 865-869.

Pape T (2009) Chapter 5. Palaearctic Diptera - from tundra to desert. In: Pape T, Bickel D,

Meier R (Eds) Diptera Diversity: Status, Challenges and Tools. Brill, Leiden - Boston: 121-154. doi: 10.1163/ej.9789004148970.I-459.27 
Papp L (1984) Family Thyreophoridae. Vol. 9. In: Soós Á, Papp L (Eds) Catalogue of Palearctic Diptera. Micropezidae-Agromyzidae. Akadémiai Kiadó, Budapest: 241-242.

Rivosecchi L (2008) Aggiunte e correzioni alle checklist di alcune famiglie di Ditteri della fauna italiana (Diptera). Bollettino della Società entomologica italiana 140 (2): 95-103

Robineau-Desvoidy JB (1830) Essai sur les myodaires. Mémoires présentés par divers Savans à l'Académie Royal des Sciences de l'Institut de France (Sciences Mathématiques et Physiques), (2) 2: $813 \mathrm{pp}$.

Robineau-Desvoidy JB (1842) Note sur le Thyreophora cynophila. Annales de la Société Entomologique de France 10, (1841): 273.

Robineau-Desvoidy JB (1849) Communication (Séance du 10 Janvier 1849). Annales de la Société Entomologique de France 7: iv-vi.

Sack P (1939) 62b. Thyreophoridae. In: Lindner E (Ed) Die Fliegen der palearktischen Region. Stuttgart: $1-7$.

Stuckenberg BR (1999) Antennal evolution in the Brachycera (Diptera) with a reassessment of terminology relating to the flagellum. Studia dipterologica 6: 33-48.

Zaldivar Ezquerro C, Rodrìguez PC, Gòmez Vargas J (2011) Thyreophora cynophila (Panzer, 1798) (Diptera: Piophilidae: Thyreophorini): distribution area in La Rioja (Spain). Boletín de la Sociedad Entomologica Aragonesa 48: 403-405. 


\section{Appendix I}

Online media coverage of recent findings of Thyreophorina in Europe: http://www.youtube.com/watch?v=gwqL02RstAw http://www.youtube.com/watch?v=QW-tOF0WtXA http://www.youtube.com/watch?v=zXgIrfwwRvg http://www.youtube.com/watch?v=Bmqgf-TaJsQ http://www.youtube.com/watch?v=eCm9I_G7HI http://www.youtube.com/watch?v=p1QcpliZm3g http://www.youtube.com/watch?v=gGqGAEUDFUU http://www.youtube.com/watch?v=NnECVsursMs http://www.diptera.info/forum/viewthread.php?forum_id=5\&thread_id=46137 http://www.diptera.info/forum/viewthread.php?forum_id=5\&thread_id=26429 http://www.diptera.info/forum/viewthread.php?forum_id=22\&thread_id=12704 http://www.diptera.info/forum/viewthread.php?forum_id=5\&thread_id=11348 http://www.diptera.info/forum/viewthread.php?forum_id=5\&thread_id=32315 http://www.diptera.info/forum/viewthread.php?forum_id=128thread_id=32317 http://www.diptera.info/forum/viewthread.php?forum_id=5\&thread_id=26429 http://news.bbc.co.uk/earth/hi/earth_news/newsid_9008000/9008585.stm 